\title{
COLLAGEN ANALYSIS OF GRAFT IN BONE TUNNEL MODEL ANTERIOR CRUCIATE LIGAMENT (ACL) RECONSTRUCTION WITH INTRATUNNEL ALLOGENIC BONE MARROW MESENCHYMAL STEM CELLS (MSCS) AND VASCULAR ENDOTHELIAL GROWTH FACTOR (VEGF)
}

\section{Petrasama}

Department of Orthopaedic, Faculty of Medicine, Airlangga University -Dr. Soetomo Hospital, Surabaya, Indonesia.

\begin{abstract}
ACL reconstruction measures aim to obtain stable knees, and reduce the risk of further injury to the meniscus and joint surfaces. Acceleration of the integration process between the tendon graft and the bone tunnel will improve the final result of ACL reconstruction. The purpose of this study was to investigate the collagen composition of the bone tunnel graft model of anterior cruciate ligament reconstruction with intravenous allogenic bone marrow mesenchymal stem cells and vascular endothelial growth factor in experimental animals. The design of this study was Post-test only Control Group Design using 20 rabbits divided into treatment group and control group. Collagen immunohistochemical evaluation was performed at weeks 3 and 6. Evaluation at week 3 obtained the area of collagen type- 1 in the higher treatment group at treatment $(p<0.001)$. In the 6th week evaluation, it was found that the area of collagen type-1 in the treatment group was higher $(\mathrm{p}<0.05)$. Type-1 collagen at week 6 did not differ significantly with week 3 ( $p>0.05$ ). Provision of allogenic bone marrow mesenchymal stem cells and intratonal vascular endothelial growth factor in ACL reconstruction enhanced the formation of collagen type- 1 which is the acceleration of incorporation of the graft tendon process with bone tunnel.
\end{abstract}

Keywords : Anterior Cruciate Ligament, allogenic bone marrow mesenchymal stemcells, vascular endothelial growth factor, graft and collagen.

\section{INTRODUCTION}

Recovery after the ACL reconstruction action will take 6-12 months postoperatively to undergo a gradual rehab program before returning to practice. Anterior Cruciate Ligament (ACL) reconstruction surgery uses a tendon graft inserted into the tunnel of the femur and tibia bones to reconstruct a ruptured ACL. Collagen makes up $30 \%$ of the extracellular matrix. Type I collagen is 8090\% obtained in ligaments and has a very large tensile strength and the remaining $10 \%$ is collagen type III (Pastides \& Khan, 2011).

The process of graft integration with bone and remodeling graft (ligamentisation) is required to achieve graft healing. Mesenchymal stem cells are able to secrete various growth factors that contribute to the activation and recruitment of fibroblast precursors and increase the synthesis of extracellular matrices (Yu et al., 2011). Giving 
vascular endothelial growth factor will promote neovascularization, stimulate fibroblast cell proliferation, collagen synthesis, and growth of bone-tunnel lettuce (Deehan \& Cawston, 2005). The provision of mesenchymal stem cells and vascular endothelial growth factor in the bone tunnel has the potential to accelerate the process of

\section{METHODS}

This research was true experimental laboratory where control group and treatment group were analyzed by independent T-test one-sample test. This research was conducted for 6 weeks in Stem Cell Research and Development Center of Airlangga University. The research design used in this study was The Post-test only Control Group Design. The research subjects consisted of 20 animals

\section{RESULTS}

It was found that in the control group evaluated after 3 weeks, the average area of collagen type-1 on immunohistochemical examination the graft to bone healing which can be evaluated by changing the composition of collagen type I on the tendon graft interface in the bone tunnel. So this study aims to determine the effect of stem cell and vascular endothelial growth factor on changes in the extracellular matrix on graft bone tunnel model of ACL reconstruction.

divided into 2 (two) groups randomly based on observation time of 3 and 6 weeks.

Experimental unit was the white rabbit (Oryctolagus cuniculus) adult, male, aged 6-9 months, from breeding, weight scales torbal (Torsion Balance), with a healthy condition characterized by an active movement, stool (faeces) was not mushy, no weight loss of more than $10 \%$ during acclimatization and response to stimuli around.

was $4.25 \pm 0.79057 \mathrm{~mm} 2$ in the femur and in the bone $4,56 \pm 0.31458 \mathrm{~mm} 2$ in the tibia.

Table 1. Total Area Collagen type -1 in Control Group of 3 Weeks Treatment

\begin{tabular}{|c|c|c|c|c|c|c|c|c|c|c|c|c|}
\hline \multirow{2}{*}{ No } & \multirow{8}{*}{ Sample } & \multicolumn{10}{c|}{ Evaluation ( Control : 3 weeks) } & \multirow{2}{*}{ Mean } \\
\cline { 3 - 14 } & & $\mathbf{1}$ & $\mathbf{2}$ & $\mathbf{3}$ & $\mathbf{4}$ & $\mathbf{5}$ & $\mathbf{6}$ & $\mathbf{7}$ & $\mathbf{8}$ & $\mathbf{9}$ & $\mathbf{1 0}$ & \\
\hline $\mathbf{1}$ & Sample1.F & 2,5 & 5 & 5 & 5 & 7,5 & 5 & 2,5 & 10 & 5 & 5 & 5,25 \\
\hline $\mathbf{2}$ & Sample 2.F & 2,5 & 2,5 & 5 & 5 & 2,5 & 2,5 & 2,5 & 5 & 5 & 2,5 & 3,5 \\
\hline $\mathbf{3}$ & Sample 3.F & 2,5 & 5 & 5 & 2,5 & 2,5 & 2,5 & 7,5 & 5 & 2,5 & 2,5 & 3,75 \\
\hline $\mathbf{4}$ & Sample 4.F & 5 & 5 & 7,5 & 2,5 & 5 & 5 & 2,5 & 2,5 & 5 & 5 & 4,5 \\
\hline \multicolumn{8}{|c|}{ The average area (femur) (Mean \pm SD): $4,25 \pm 0,79057$} \\
\hline $\mathbf{1}$ & Sample 1.T & 5 & 5 & 7,5 & 2,5 & 2,5 & 2,5 & 2,5 & 5 & 10 & 2,5 & 4,5 \\
\hline $\mathbf{2}$ & Sample2.T & 2,5 & 5 & 5 & 2,5 & 2,5 & 7,5 & 7,5 & 5 & 2,5 & 2,5 & 4,25 \\
\hline $\mathbf{3}$ & Sample3.T & 7,5 & 7,5 & 5 & 2,5 & 5 & 5 & 7,5 & 2,5 & 2,5 & 5 & 5,0 \\
\hline $\mathbf{4}$ & Sample 14.T & 2,5 & 2,5 & 2,5 & 7,5 & 7,5 & 2,5 & 2,5 & 5 & 5 & 7,5 & 4,5 \\
\hline
\end{tabular}

Ket. F: Femur T : Tibia The average area (tibia) $($ Mean \pm SD) : 4,56 $\pm 0,31458$ 
Table 2. Area of Type-1 Collagen Area in Control Group of 6 Weeks Treatment

\begin{tabular}{|c|c|c|c|c|c|c|c|c|c|c|c|c|}
\hline \multirow{2}{*}{ No } & \multirow{8}{*}{ Sample } & \multicolumn{10}{c|}{ Evaluation ( Control : 6 weeks) } & \multirow{2}{*}{ Mean } \\
\cline { 2 - 14 } & & $\mathbf{1}$ & $\mathbf{2}$ & $\mathbf{3}$ & $\mathbf{4}$ & $\mathbf{5}$ & $\mathbf{6}$ & $\mathbf{7}$ & $\mathbf{8}$ & $\mathbf{9}$ & $\mathbf{1 0}$ & \\
\hline $\mathbf{1}$ & Sample 1.F & 5 & 2,5 & 5 & 2,5 & 2,5 & 2,5 & 7,5 & 5 & 2,5 & 5 & 4,0 \\
\hline $\mathbf{2}$ & Sample 2.F & 10 & 2,5 & 5 & 5 & 7,5 & 5 & 5 & 5 & 2,5 & 2,5 & 5,0 \\
\hline $\mathbf{3}$ & Sample 3.F & 5 & 5 & 7,5 & 7,5 & 5 & 5 & 2,5 & 5 & 5 & 7,5 & 5,5 \\
\hline \multicolumn{8}{|c|}{ The Average area (femur) (Mean+SD) $: 4,83 \pm 0,76376$} \\
\hline $\mathbf{1}$ & Sample 1.T & 5 & 5 & 7,5 & 2,5 & 2,5 & 2,5 & 2,5 & 5 & 10 & 2,5 & 4,5 \\
\hline $\mathbf{2}$ & Sample2.T & 2,5 & 5 & 5 & 2,5 & 2,5 & 7,5 & 7,5 & 5 & 2,5 & 2,5 & 4,25 \\
\hline $\mathbf{3}$ & Sample 3.T & 7,5 & 7,5 & 5 & 2,5 & 5 & 5 & 7,5 & 2,5 & 2,5 & 5 & 5,0 \\
\hline
\end{tabular}

Ket. F: Femur T : Tibia The average area area (tibia) $($ Mean \pm SD) $: 4,75 \pm 0,5000$

It was found that in the control group evaluated after 3 weeks, the average area of collagen type-1 on immunohistochemical examination was $4: 25 \pm 0.79057 \mathrm{~mm} 2$ in the femur and in the bone $0.31458 \pm 4.56 \mathrm{~mm} 2$ in the tibia.

Table 3. Total Area Collagen type -1 In 3 Weeks Control group

\begin{tabular}{|c|c|c|c|c|c|c|c|c|c|c|c|c|}
\hline \multirow{2}{*}{ No } & \multirow{2}{*}{ Sample } & \multicolumn{10}{|c|}{ Evaluation ( Treatment : 3 weeks) } & \multirow{2}{*}{ Mean } \\
\hline & & 1 & 2 & 3 & 4 & 5 & 6 & 7 & 8 & 9 & 10 & \\
\hline 1 & Sample 1.F & 15 & 15 & 10 & 12,5 & 12,5 & 15 & 10 & 12,5 & 12,5 & 7,5 & 12,25 \\
\hline 2 & Sample 2.F & 7,5 & 7,5 & 10 & 10 & 10 & 5 & 10 & 10 & 7,5 & 12,5 & 9,0 \\
\hline 3 & Sample 3.F & 7,5 & 10 & 10 & 10 & 12,5 & 10 & 5 & 12,5 & 12,5 & 10 & 10 \\
\hline 4 & Sample 4.F & 7,5 & 7,5 & 10 & 10 & 10 & 7,5 & 7,5 & 12,5 & 12,5 & 10 & 9,5 \\
\hline 5 & Sample 5.F & 12,5 & 10 & 7,5 & 7,5 & 10 & 5 & 5 & 7,5 & 12,5 & 10 & 8,75 \\
\hline \multicolumn{13}{|c|}{ Average area (femur) $($ Mean \pm SD) $: 9,9 \pm 1,39866$} \\
\hline 1 & Sample1.T & 7,5 & 7,5 & 10 & 10 & 10 & 7,5 & 12,5 & 12,5 & 7,5 & 12,5 & 9,75 \\
\hline 2 & Sample2.T & 7,5 & 7,5 & 10 & 10 & 5 & 7,5 & 12,5 & 5 & 5 & 10 & 8,0 \\
\hline 3 & Sample3.T & 7,5 & 7,5 & 5 & 10 & 7,5 & 5 & 10 & 10 & 12,5 & 10 & 8,5 \\
\hline 4 & Sample 4.T & 12,5 & 12,5 & 12,5 & 10 & 7,5 & 5 & 15 & 10 & 10 & 10 & 10,5 \\
\hline 5 & Sample5.T & 7,5 & 7,5 & 10 & 10 & 5 & 5 & 7,5 & 7,5 & 12,5 & 10 & 8,25 \\
\hline
\end{tabular}

It was found that control treatment evaluated after 3 weeks, the average area of collagen type 1 on immunohistochemical examination was
9,9 $\pm 1,39866 \mathrm{~mm}^{2}$ on femur and bone was $9 \pm$ $1,07529 \mathrm{~mm}^{2}$.

Table 4. Collagen Type Area Size -1 In treatment Group 3 weeks

\begin{tabular}{|c|c|c|c|c|c|c|c|c|c|c|c|c|}
\hline \multirow{2}{*}{ No } & \multirow{8}{*}{ Sampel } & \multicolumn{10}{|c|}{ Evaluation (Treatment : 3 weeks) } & \multirow{2}{*}{ Mean } \\
\cline { 2 - 14 } & & $\mathbf{1}$ & $\mathbf{2}$ & $\mathbf{3}$ & $\mathbf{4}$ & $\mathbf{5}$ & $\mathbf{6}$ & $\mathbf{7}$ & $\mathbf{8}$ & $\mathbf{9}$ & $\mathbf{1 0}$ & \\
\hline $\mathbf{1}$ & Sample 1.F & 5 & 7,5 & 7,5 & 5 & 2,5 & 7,5 & 7,5 & 2,5 & 5 & 2,5 & 5,25 \\
\hline $\mathbf{2}$ & Sample 2.F & 10 & 10 & 2,5 & 2,5 & 5 & 7,5 & 7,5 & 10 & 10 & 7,5 & 7,25 \\
\hline $\mathbf{3}$ & Sample 3.F & 10 & 7,5 & 7,5 & 12,5 & 10 & 5 & 7,5 & 7,5 & 5 & 7,5 & 8,0 \\
\hline $\mathbf{4}$ & Sample 4.F & 5 & 5 & 10 & 7,5 & 5 & 10 & 10 & 12,5 & 5 & 2,5 & 7,25 \\
\hline $\mathbf{5}$ & Sample 5.F & 10 & 10 & 7,5 & 12,5 & 12,5 & 10 & 10 & 7,5 & 7,5 & 5 & 8,25 \\
\hline $\mathbf{6}$ & Sample 6.F & 7,5 & 10 & 10 & 12,5 & 12,5 & 10 & 7,5 & 15 & 12,5 & 12,5 & 11,0 \\
\hline \multicolumn{10}{|c|}{ Rerata Luas area (femur) (Mean \pm SD) : $7,8 \pm 1,87528$} \\
\hline $\mathbf{1}$ & Sample1.T & 7,5 & 7,5 & 10 & 10 & 5 & 7,5 & 10 & 2,5 & 2,5 & 7,5 & 7,0 \\
\hline
\end{tabular}




\begin{tabular}{|l|l|l|l|l|l|l|l|l|l|l|l|l|}
\hline $\mathbf{2}$ & Sample2.T & 7,5 & 10 & 12,5 & 10 & 5 & 7,5 & 7,5 & 12,5 & 10 & 5 & 8,75 \\
\hline $\mathbf{3}$ & Sample3.T & 10 & 10 & 12,5 & 12,5 & 10 & 10 & 5 & 10 & 7,5 & 7,5 & 9,5 \\
\hline $\mathbf{4}$ & Sample4.T & 7,5 & 12,5 & 12,5 & 7,5 & 5 & 5 & 2,5 & 2,5 & 10 & 7,5 & 7,25 \\
\hline $\mathbf{5}$ & Sample5.T & 7,5 & 7,5 & 12,5 & 10 & 12,5 & 12,5 & 5 & 10 & 5 & 7,5 & 9,0 \\
\hline $\mathbf{6}$ & Sample6.T & 12,5 & 7,5 & 7,5 & 12,5 & 10 & 7,5 & 7,5 & 7,5 & 5 & 5 & 8,25 \\
\hline \multicolumn{8}{|c|}{ Ket. F: Femur T: Tibia Average area (tibia) (Mean \pm SD) $: 8,2 \pm 0,99268$} \\
\hline
\end{tabular}

Was found that the treatment group were evaluated after 6 weeks is obtained, the average area of collagen type-1 immunohistochemical examination was $7,8 \pm 1.87528 \mathrm{~mm}^{2}$ at the bone of the femur and $8.2 \pm 0,99268 \mathrm{~mm}^{2}$ on the tibia.

There was significant difference between mean extensive collagen in the treatment groups and control group for 3 weeks treatment $(\mathrm{p}<0.001)$. Mean extensive collagen in the treatment groups for 3 weeks tibia higher

\section{DISCUSSION}

Surgery ACL reconstruction aims to regain knee mechanically stable, lowers the risk of further injury to the meniscus and the surface of joints by reducing joint movement anteroposterior (Myklebust \& Bahr, 2005).reconstruction surgery The anterior cruciate ligament (ACL) using a graft tendon were inserted into the tunnel in the femur and tibia to reconstruct a ruptured ACL. Bone formation, graft remodeling and integration with bone graft determines the mechanical strength of the graft in ACL reconstruction (Lui et al., 2010). The process of rapid integration between the graft tendon to bone tissue in the bone tunnel to obtain sufficient mechanical strength will improve the outcome of ACL reconstruction (Kanazawa et al., 2012). than the control group and this difference was statistically significant ( $\mathrm{p}<0.001)$. Mean extensive collagen in the treatment group during the 6-week femur is greater than the control group and this difference was statistically significant $(\mathrm{P}<0.05)$. Mean extensive collagen in the treatment group during the 6-week tibia greater than the control group and these differences were significant statistically $(\mathrm{P}<0.05)$.

This research isstudy true experimental aimed to analyze the extensive formation of collagen type-1 histologically the graft tendonin amodel ofbone tunnel ACL reconstruction with allogenic bone marrow mesenchymal stem cells (MSCs) and vascular endothelial growth factor (VEGF) in intratunnel. Time observations were made at week 3 and week 6 based on research by Tomita et al 2001. At week 3 necrosis in a graph and granulation tissue contained between the graft to the wall of the bone tunnel. At week 6 obtained bone formation at the interface graft with bonetunnel and pembentukan serabut yan perpendicular collagen connects graft tendonto the bonetunnel together with granulation tissue on the tendon. Fiber. This collagen is composed resembles Sharpey's fibers (Ouyang et al., 
2004; Zelle et al., 2005). MSCs were able to secrete various growth factors that contribute to the activation and recruitment of fibroblast precursors and increasing the synthesis of extracellular matrix (Yu et al., 2011). Relatively a vascular condition of graft the tendonis one of the factors that lead process to bone graft healing is not optimal and improve network degradation (Lui et al., 2010).

Administration VEGF will encourage neovaskulerisasi, stimulates proliferation of fibroblasts, collagen synthesis and growth of lettuce bone tunnel (Deehan \& Cawston,2005). The results of the comparative analysis on penelitianini $\mathrm{T}$ test showed significant difference between control and treatment groups at week $3(\mathrm{p}=0.000)$ and at week $6(\mathrm{p}$ $=0.036)$.However comparative analysis by $\mathrm{T}$ test between the treatment weeks to 3 and week 6 showed meaningful differences. Treatment 3rd week has extensive formation of collagen type- 1 greater $\left(9.90 \mu \mathrm{m}^{2} \pm 1: 39\right)$ compared to week $6\left(7.83 \mu \mathrm{m}^{2} \pm 1.87\right)$.

In this study, an increase in the formation of collagen type-1 significantly in the treatment group. Increased formation of collagen type-1 were significantly indicates the acceleration of the process of integration of the graft to the bone tunnel (Pastides \& Khan, 2011). Early stages immediately after the reconstruction is the result of traumatic necrosis drilling of bonetunnel. Tendon graft inside the bone tunnel will experience stages of the healing process (Lui et al., 2010). Ischemic Necrosis will be followed by an acute inflammatory process, chronic inflammatory cell recruitment and, revaskulerisation and cell proliferation and remodeling collagen (Deehan \& Cawston, 2005).

In this study, a decrease in the area of collagen type-1 at week 6 compared to weeks to 3 although the statistical analysis showed no significant difference. The integration process graft with and the bone remodeling of graft (ligamentation) required to achieve healing of the graft.The decline in the area of collagen type-1 at week 6can be attributed to the formation of a layer chondroid at week 2 yang contain lots of collagen type 2 and persanan cells and deposed chondroid the matrix collagen type-2 (Kanazawa et al.,2012). Research Kanazawa et al mengeluasi interface bone with a tendon in ACL reconstruction rabbit experimental animals at weeks 1, 2, 4 and 8 . In the first week of granulation tissue is dominated by the formation collagen type-1 are minimal. In the second week up to 4 expression of collagen type-1 increased along with the establishment chondroid the layer that contains collagen type 2 and Sharpey-like fibers comprising of collagen type-3. The formation of collagen type-3 will be increased at week 8 in which this week began the process of remodeling of the graft (Kanazawa et al.,2012). 


\section{CONCLUSION}

The provision of allogenic Mesenchymal Stem Cells (MSCs) and Vascular Endothelial Growth Factor (VEGF) intratunnel the models bonetunnel ACL reconstruction significantly increase the area of collagen type- 1 on the

\section{REFERENCES}

Ardern C, Taylor N, Feller J, Webster K. 2012. Return-to-sport Outcomes at 2 to 7 years anterior cruciate Lihgament After Reconstruction Surgery. American Journal of Sports Medicine. January; 40 (1): p. 41-48.

Changlong Y, Lin L, Wei X. 2011. The Different Effects of TGF- $\beta 1$, VEGF and PDGF on the remodeling of anterior cruciate ligament graft, Targets in Gene Therapy. In You Y. Targets in Gene Therapy. Shanghai: Intechopen.

Deehan DJ, Cawston TE. 2005. The Biology of Integration of anterior cruciate ligament. British Editorial Society of Bone and Joint Surgery; 87 (B): p. 889-895.

Dordevic M, Hirschmann MT. 2014. Mechanism of Injury ACL Tear. In Siebold R. anterior cruciate ligament Reconstruciton A Practical Gudie. New York: Springer Heidelberg; p. 49-52.

Kjaer M, Krogsgaard M, Magnusson P, Engebretsen L, Roos H, Takala T, et al., Editors. Textbook of Sports tissue graft tendon with bonetunnel. Increased collagen type-1 area indicates more the number of collagen tissue at the graft interface tendon with bonetunnel, along with the process incorporation graft tendon with bonetunnel earlier.

Medicine. Oxford: Blackwell; p. 561.

Kanazawa T, Soejima T, Tabuchi K. 2012. histological analysis on the tendon-tobone healing utilizing bone marrowderived MSCs in ACL reconstruction without amodels. bone tunnel ORS 2012 Annual Meetin; 1341.

Kweon C, Lederman ES, Chhabra A. 2013. Anatomy and Biomechanics of the cruciate ligaments and Their Implications Surgical. In G. Fanelli he MultipleLigament: Injured Knee A Practical Guide to Management. New York: Springer Science; p. 17-26.

Lui PPY, Zhang P, Chan KM, Qin L. 2010. Biology and Augmentation of TendonBone Repair Insertion. Journal of Orthopedic Surgery and Research. August; 5 (59): p. 1-14.

Myklebust G, Bahr R. 2005. Return to Play Guidelines AfterThe anterior cruciate Surgery ligament. British Journal of Sports Medicine. April; 39 (3): p. $127-$ 131.

Ouyang HW, Goh J, Lee EH. 2004. Use of Bone Marrow Stromal Cells for Tendon Graft-to-Bone Healing histological and immuno 
histochemical Studies in a Rabbit Model. The American Journal of Sports Medicine; 32 (2): p. 321-326.

Pastides PS, Khan W. 2011. Tendon and Ligament Injuries: The Evolving Role of Stem Cells and Tissue Engineering. British Journal of Medicine and Medical Research; 1 (4): p. 569-580.

Petersen W, Tilllmann B. 1999. Structure and Vascularization of cruciate ligaments of the Human Knee Joint. Anatomy Embryology; 200: p. 325-344.

Tomita M, Yasuda K, Mikami S, Sakai T, Yamazaki S, Tohyama H. 2001. Comparisons of intraosseous Graft Healing Doubled Between the flexor tendon graft and the Bone-patellar tendon-bone graft in anterior cruciate ligament Reconstruction. Arthroscopy: The Journal of Arthroscopic and Related Surgery; 17 (5).

Yu C, Lin L, Wei X. 2011. The Different Effects of TGF- $\beta 1$, VEGF and PDGF on the remodeling of anterior cruciate ligament graft. In Yongping Y, editor. Gene Therapy. Shanghai: Intech; p. 390-396.

Zelle B, Lattermann C, Chhabra A, Fu F, Huard J. 2005. Biological Considerations of Tendon Graft Incorporation Within the Bone Tunnel. Operative Techniques in Orthopedics; 15: p. 36-42. 